\title{
Influence of cement slurry heat release on physical properties of marine hydrate reservoirs during well cementing
}

\author{
Mingming Zheng ${ }^{1,2, *}$, Xiaoyu Wang ${ }^{1}$, Zhilin Wang ${ }^{1}$, Kerui Zhou ${ }^{1}$, Kai Wang ${ }^{1}$, Gang Dong ${ }^{3}$ and Tianle Liu ${ }^{4}$, \\ ${ }^{1}$ State Key Laboratory of Geohazard Prevention and Geoenvironment Protection, Chengdu University of Technology, Chengdu 610059, \\ China \\ ${ }^{2}$ Key Laboratory of Tectonics and Petroleum Resources Ministry of Education, China University of Geosciences(Wuhan), Wuhan 430074, \\ China \\ ${ }^{3}$ Qinghai Research Institute of Survey and Design of Water Conservancy and Hydropower, Xining 810012, China \\ ${ }^{4}$ Engineering Research Center of Rock-Soil Drilling \& Excavation and Protection, Ministry of Education, China University of Geosciences \\ (Wuhan), Wuhan 430074, China
}

\begin{abstract}
Natural gas hydrates gradually become the focus of new energy resources, and the study of hydrate exploitation is growing vigorously during recent years. Well cementing is an important process during energy exploitation, especially when encounters hydrate bearing sediments in deep-water oil and gas drilling, showing great research significance and becoming a research hotspot. In this study, the exploratory well of SH2 of GMGS-1 project is chosen as the object of study, a cementing model of two dimensions based on this exploratory well is build, the invasion process of cement slurry is reappeared by TOUGH+HYDRATE, and the physical properties response of hydrate reservoirs during the cementing process is analyzed based on the numerical simulation data. In which, a view of "continuous stage simulation" to solve the problem of dynamic heat release of cement slurry is created and used for the first time. Result illustrated that the invasion behavior of cement slurry almost only occurred during the stage of holding pressure, the temperature has significantly increased in the area of reservoir which is invaded by cement slurry. At the same time, a large amount of decomposed hydrate have generated gas and water, which form high pressure region and transfer toward the deeper of reservoir. However, the variation in the temperature is not significant and the hydrate barely no longer decomposed in those area which outside or even though close to this area. There also have generated secondary hydrate closed to the area of decomposition and formed high saturation zone of hydrate. The results also proved the feasibility of "continuous stage simulation", and played a guiding significance for the field well cementing.
\end{abstract}

\section{Introduction}

Natural gas hydrate is an ice-like compound formed by water molecules and natural gas molecules at low temperature and high pressure [1]. As a typical unconventional energy, it has attracted widespread attention because of its huge reserves and more environment-friendly advantage. So the exploitation of hydrate becomes a focus of research ${ }^{[2-4]}$, in which, well cementing has important meanings in the aspect of stabilizing the well wall and extending the life of the production well ${ }^{[5-7]}$. Because of its special phase equilibrium condition, the reserve of natural gas hydrate usually locate in permafrost or marine sediments where the formations has the property of weak cementation and poor mechanical strength. These are all the issues that need to be well considered during the cementing process. Afterwards, what more complicated is the hydration exotherm of cement slurry extreme easily trigger the decomposition of hydrate and further form high-pressure gas and water region. This will lead to cementing quality problems, such as well wall collapse, methane leakage or others, shown as in Figure 1.

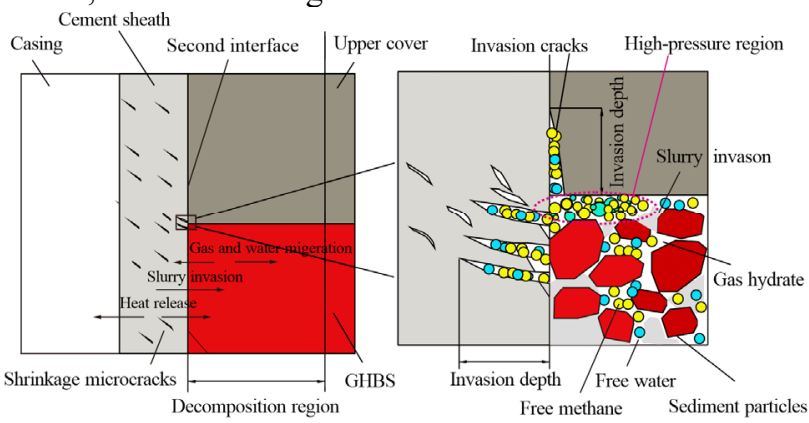

Fig1. Schematic diagram of cement slurry invading into hydrate reservoir.

The effects of well cementing on hydrate reservoir mainly comes from the heat conduction and fluid invasion, currently the most relevant research which almost focused on drilling fluid invasion and heat injection exploitation. Kamath et al ${ }^{[8]}$ carried out exploitation experiments by injection of hot brine and got a conclusion that salinity has 
a significant effect on thermal decomposition. Based on the theory of multi-field coupling, Zhai et al ${ }^{[9]}$ studied change law of main physical properties with the deformation and failure of near-well hydrate reservoirs under heat injection conditions by numerical simulation, established a thermo-fluid-solid coupling elastoplastic model that can reflect the coupling of temperature field, seepage field and deformation field. Hao et al [10] conducted experiments of gas recovery by heat injection, and compared with the calculation results of Selim Analytical Model, obtained the main heat transfer methods that control the movement of the temperature front are the heat convection and heat conduction. Zheng et $\mathrm{al}^{[11]}$ conducted drilling fluid invasion experiments, and quantitatively analyzed the changes of temperature, pressure, resistivity and the decomposition depth of gas hydrate bearing sediments (GHBS), obtained that the maximum invasion depth in 12 hours is $0.65 \mathrm{~m}$. Zhang et $\mathrm{al}^{[12]}$ used ultrasonic testing methods to respectively study the process of two kinds of drilling fluids invading into hydrate bearing rock samples, explored the disturbance law of hydrate thermodynamic inhibitor to GHBS. Because of the similarity of process and principle, the above research should generate certain guiding meaning to physical properties response of hydrate reservoir during the process of well cementing. However, the feature that cement slurry not only invading the reservoir but also serving as a new exothermic source during the process which make the process more complicated ${ }^{[13]}$.

Therefore, research on well cementing involving mass and heat transfer will be of great significance. This study takes the exploration well SH2 of GMGS-1 gas hydrate drilling project in Shenhu area, South China Sea as the research object, aiming at the issues of cement slurry as a mobile heat source invading into the reservoir during well cementing. TOUGH+HYDRATE, a numerical simulation software for multiphase flow involving phase change developed by the Lawrence Berkeley State Key Laboratory of the United States ${ }^{[14]}$, is used to establish a one-dimensional model of well cementing for hydrate reservoirs, carry out numeral calculations and analyze the change law and influence mechanism of main physical properties of hydrate reservoirs.

\section{Study area selection}

The South China Sea has vast area with a considerable amount of hydrate resources buried in. In the year of 2007, the Ministry of Land and Resources implemented the gas hydrate drilling project GMGS-1 for the first time in the Shenhu area of the South China Sea, completed the drilling and logging work for 8 drilling positions, and respectively acquired natural gas hydrate samples from $\mathrm{SH} 2, \mathrm{SH} 3$ and SH $7^{[15,16]}$. Because of the detailed data of logging and core analysis at station $\mathrm{SH} 2$, it is selected as the study object, the location is shown in Figure 2. According to the results of sample analysis and logging ${ }^{[17-}$ ${ }^{19]}$, the hydrate layer at this station is mainly located below the seafloor with a depth from 185 to $229 \mathrm{~m}$, and the thickness of the hydrate reservoir is about $44 \mathrm{~m}$, the sea water depth is about $1235 \mathrm{~m}$. The average porosity is $40 \%$ and the peak is up to $47 \%$, the seabed temperature is about $4^{\circ} \mathrm{C}$, and the geothermal gradient is $46.9^{\circ} \mathrm{C} / \mathrm{km}$. Except for a small amount of fine sand near the seabed, the reservoir is mainly silty clay.

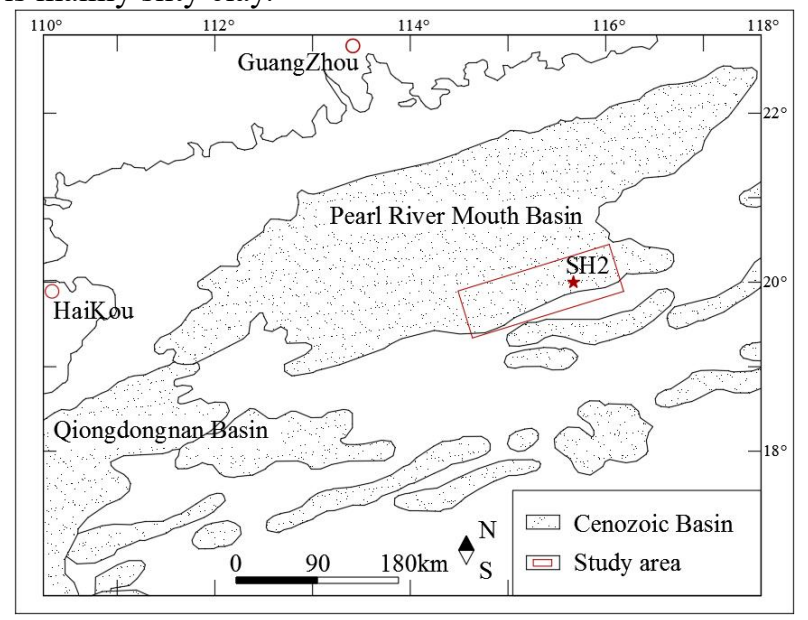

Fig2. Location map of the GMGS-1 project in the Shenhu area of the South China Sea ${ }^{[20]}$.

\section{Numerical simulations}

\subsection{Numerical methods}

TOUGH+HYDRATE is a professional multiphase flow simulation software for hydrate reservoir, including both equilibrium and kinetic models of hydrate formation and dissociation. The models consider heat and four mass components, namely water, methane, hydrates and watersoluble inhibitors (e.g., salts or alcohols), which are subdivided into four possible phase states (gas, liquid, ice and hydrate phases). This model can fully describe the dissociation or formation of hydrates, phase changes and the influence of corresponding thermal effect and inhibitors. All possible mechanisms of hydrate dissociation can be described, i.e., depressurization, thermal stimulation, salt segregation effects and inhibitorinduced effects ${ }^{[14]}$. The key equations used are as follows:

Relative permeability model ${ }^{[21]}$ :

$$
\begin{gathered}
k_{r A}=\max \left\{0, \min \left[\left(\frac{S_{A}-S_{i r A}}{1-S_{i r A}}\right)^{n}, 1\right]\right\} \\
k_{r G}=\max \left\{0, \min \left[\left(\frac{S_{G}-S_{i r G}}{1-S_{i r A}}\right)^{n_{G}}, 1\right]\right\} \\
k_{r H}=0
\end{gathered}
$$

where,

$k_{r A}$ is the liquid-phase relative permeability; $k_{r G}$ is the gas-phase relative permeability; $S_{A}$ is the liquid-phase saturation; $S_{G}$ is the gas-phase saturation; $S_{i r A}$ is the bound water saturation and takes the value of $0.12 ; S_{i r G}$ is the bound gas saturation and takes the value of $0.02 ; n=n_{G}=3.0$.

Capillary pressure model ${ }^{[22]}$ :

$$
\begin{gathered}
P_{\text {cap }}=-P_{0}\left[\left(S^{*}\right)^{-1 / \lambda}-1\right]^{1-\lambda} \\
S^{*}=\frac{\left(S_{A}-S_{\text {irA }}\right)}{\left(S_{m x A}-S_{\text {irA } A}\right)} \\
-P_{\text {max }} \leq P_{\text {cap }} \leq 0
\end{gathered}
$$


where,

$P_{c a p}$ is the capillary pressure; $\lambda$ is $0.45 ; S_{i r A}$ is $0.11 ; S_{\max }$ is the maximum liquid phase saturation, which is $1.0 ; P_{0}$ is the initial pressure, which is $1.25 \times 10^{4} \mathrm{~Pa}$, and $P_{\max }=10^{6}$ Pa.

The comprehensive thermal conductivity of the formation $\lambda \mathrm{c}$ can be calculated as ${ }^{[23]}$ :

$$
\lambda_{c}=\lambda_{H s}+\left(\sqrt{S_{A}}+\sqrt{S_{H}}\right)\left(\lambda_{s}-\lambda_{H s}\right)+\varphi S_{I} \lambda_{I}
$$

where,

$S_{H}$ is the hydrate saturation; $\lambda_{H s}$ is the thermal conductivity of the sediment containing only hydrates; $\lambda_{s}$ is the thermal conductivity of the water-saturated sediment; $\lambda_{I}$ is the thermal conductivity of ice; $\varphi$ is the porosity. No ice is present at this simulated temperature, so, $S_{I}=0$.

\subsection{Main parameters setting}

The numerical model of the reservoirs is established in a two-dimensional cylindrical coordinate system, with a borehole diameter of $140 \mathrm{~mm}$. The outer diameter of the casing is $120 \mathrm{~mm}$ and the thickness is $6 \mathrm{~mm}$, thence, the annulus space thickness is $20 \mathrm{~mm}$. According to the reported research ${ }^{[13]}$, the influence range of the cementing process on the formation is not deep, to be conservative, the model radius is taken as $5 \mathrm{~m}$. It is assuming that the formation is homogeneous, a thin layer with a thickness of $0.1 \mathrm{~m}$ can be used for simulation analysis to obtain valid results. Since the changes of physical properties near the well wall are the most drastic, the grid of the formation should be refined. In addition, the annulus space and the casing are each demarcated as a unit. And the casing unit can be used as an inner boundary, setting as a constant temperature and pressure boundary. The detailed meshing is shown in Figure 3.

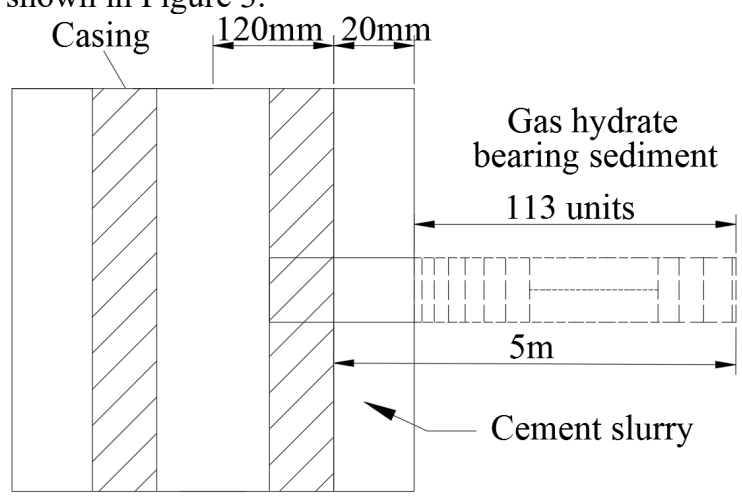

Fig3. Schematic diagram of numerical model meshing.

Table1. Main geological and technological parameters at simulated GHBS

\begin{tabular}{lclc}
\hline \multicolumn{1}{c}{ Parameters } & Value & \multicolumn{1}{c}{ Parameters } & Value \\
\hline Depth (below the seabed) & $200 \mathrm{~m}$ & Thermal conductivity of sediment with saturated water & $3.1 \mathrm{~W} \cdot \mathrm{m}^{-1} \cdot{ }^{\circ} \mathrm{C}^{-1}$ \\
Pore pressure & $14.5 \mathrm{MPa}$ & Thermal conductivity of sediment (without water) & $1.0 \mathrm{~W} \cdot \mathrm{m}^{-1 .}{ }^{\circ} \mathrm{C}^{-1}$ \\
Pore temperature & $13.4^{\circ} \mathrm{C}$ & Specific heat of sediment skeleton & $1000 \mathrm{~J} \cdot \mathrm{kg}^{-1 .{ }^{\circ} \mathrm{C}^{-1}}$ \\
Porosity & $40 \%$ & Temperature of cement slurry & $14.4^{\circ} \mathrm{C}$ \\
Hydrate saturation & $33.0 \%$ & Density of cement slurry & $1050 \mathrm{~kg} / \mathrm{m}^{3}$ \\
Salinity & $3.05 \%$ & Annular pressure & $14.8 \mathrm{MPa}$ \\
Absolute permeability & $1.0 \times 10^{-14} \mathrm{~m}^{2}$ & Cementing pressure difference & $3 \mathrm{MPa}$
\end{tabular}

Considering that the heat release of the cement slurry is mainly before the initial setting, the total simulation time is set as the common initial setting time of cementing slurry in deep water, which is $1680 \mathrm{~s}$. The bump plug time point is set to zero moment, the first $240 \mathrm{~s}$ is the time of pressure-holding, and the pressure is removed at $240 \mathrm{~s}$, after which the pressure naturally falls back. Since the cement slurry acts as an invasion substance as well as an exothermic source, a multi-stage simulation method is used to accurately restore the influence of "dynamic heat sources". Firstly, the entire simulation process is divided into several periods, and the duration of each segment can be adjusted according to the accuracy requirements. After that, the invasion depth in each period is calculated, and set as the initial position of the heat source in the next period, the initial data of each period is set according to the calculation results of the previous, this process continues until the end of the simulation.

According to the geological information and data mentioned in section 2, the GHBS located at a depth of $200 \mathrm{~m}$ below the seafloor is selected as simulation object. Therefore, the reservoir pore pressure is $14.5 \mathrm{MPa}$, the temperature is $13.4^{\circ} \mathrm{C}$ according to the ground temperature gradient, the sediment skeleton density is $2600 \mathrm{~kg} / \mathrm{m}^{3}$, the sediment thermal conductivity with and without saturated water are 3.1 and $1.0 \mathrm{~W} \cdot \mathrm{m}^{-1 .}{ }^{\circ} \mathrm{C}^{-1}$, the specific heat of sediment skeleton is $1000 \mathrm{~J} \cdot \mathrm{kg}^{-1 .}{ }^{\circ} \mathrm{C}^{-1}$, the porosity is $40 \%$, the hydrate saturation is taken as $33 \%$, the salinity is $3.05 \%$. Low density cement slurry with density of $1050 \mathrm{~kg} / \mathrm{m}^{3}$ is and average heat release rate of $0.35 \mathrm{~J} / \mathrm{g} \cdot \mathrm{s}$ is used. The cementing pressure difference during pressure- holding is $3 \mathrm{MPa}$. The detailed can be found in Table 1. 


\section{Result analysis and discussion}

\subsection{Variation of main physical parameters of GHBS during cement slurry invasion}

The changes of invasion depth of cement slurry with time are shown in Figure 4. It can be seen that the cement slurry rapidly invaded into the pore space during the pressureholding period under the action of pressure difference, and the invasion rate basically maintained at the same level. When the holding pressure was removed, the invasion rate dropped dramatically, and the invasion distance stagnated at about $40 \mathrm{~mm}$ and hardly invaded deep afterwards. Therefore, it can be concluded that the invasion of the cement slurry almost only occurs in the pressure-holding stage, so the active migration of cement slurry mainly only occurs at this stage
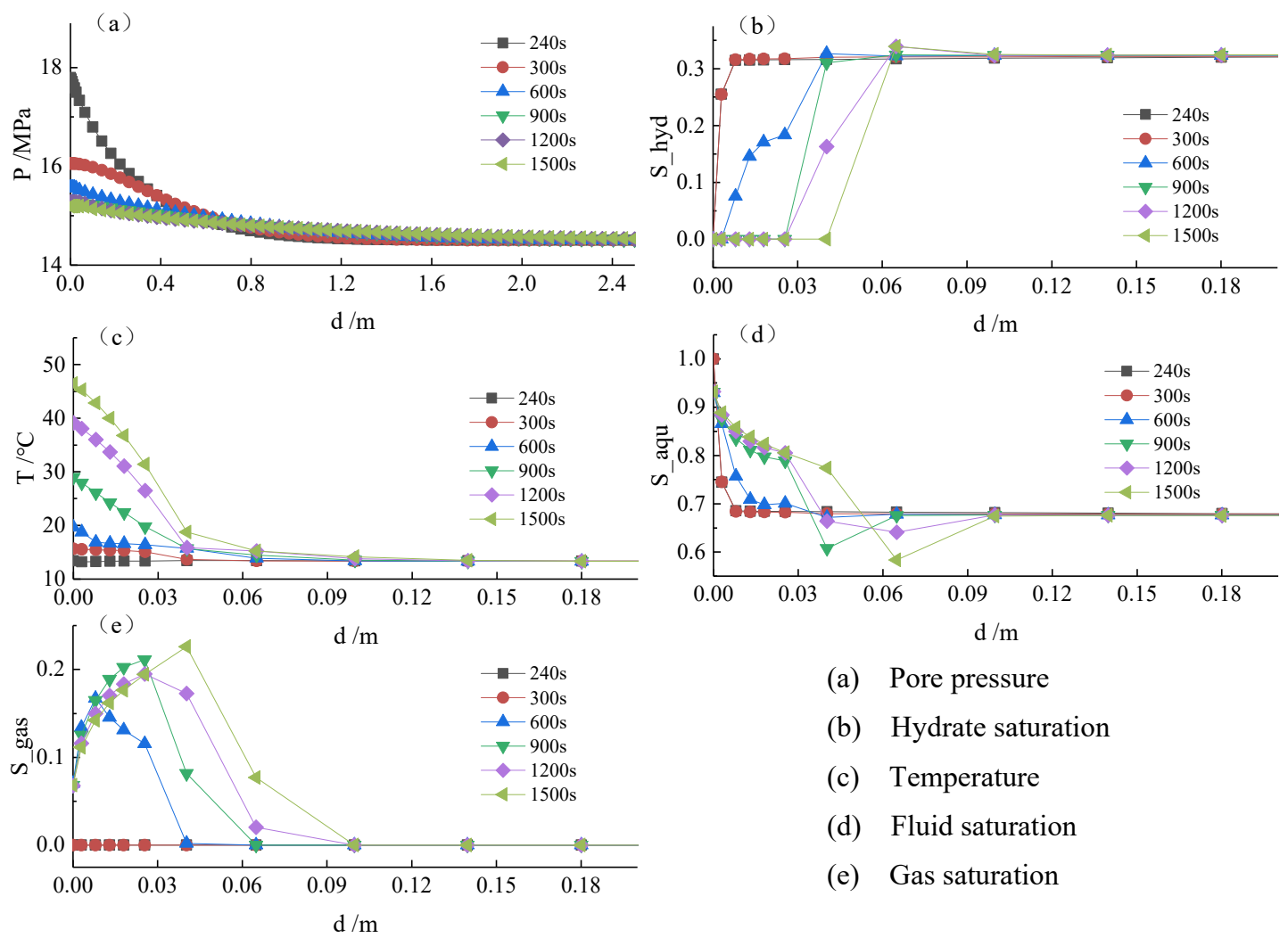

(a) Pore pressure

(b) Hydrate saturation

(c) Temperature

(d) Fluid saturation

(e) Gas saturation

Fig5. Changes in physical properties of GHBS during well cementing.

At the same time, the changes in physical properties of GHBS during well cementing is shown in Figure 5. From which it can be seen that in the pressure-holding stage, the pore pressure of the reservoir near the well wall rises rapidly, and the obvious influence range is about $0.6 \mathrm{~m}$. This is caused by the invasion of high-pressure fluid from the annulus into the formation. When the holding pressure is relieved, the pore pressure near the well wall drops rapidly, while the deep pores increase slightly. This is mainly caused by the migration of high-pressure fluid to the surrounding low-pressure area. Compared to pressure, temperature changes much slower. The temperature increase range during the pressure holding stage is only about $4 \mathrm{~cm}$, while the temperature change range during the entire simulation process is only about $10 \mathrm{~cm}$. From the saturation changes of hydrates, gases, and fluids, seen as Figures 5(b), 5(d) and 5(e), it can be found that the decomposition behavior occurs within 300-600s, and the temperature increase at this stage is relatively low, which is caused by the endothermic heat of hydrate 
decomposition. And the decomposition of hydrate mainly occurs in this stage, followed by $600-900$ s. In addition, the accompanying phenomenon is the rapid increase in gas and liquid saturation. It could be conclude that in the 300900s stage, hydrates decompose rapidly and in large amounts, and a large amount of methane and water are produced. The variation ranges of pressure and temperature, hydrate decomposition, gas and liquid saturation are respectively $1.0 \mathrm{~m}, 7 \mathrm{~cm}, 4 \mathrm{~cm}, 6.5 \mathrm{~cm}$ and $6.5 \mathrm{~cm}$.

After $900 \mathrm{~s}$, the hydrate saturation increases in the deeper depths $(6-9 \mathrm{~cm})$ next to the hydrate decomposition zone, forming an annular zone of high hydrate saturation, with maximum saturation increased to $34.5 \%$. This is because the invasion behavior makes the pressure rise here, and the temperature basically does not change, so that the phase equilibrium conditions are shifted to an area more conducive to hydrate formation. The methane gas and water produced by the decomposition of shallow hydrates migrated here and re-formed hydrates. In addition, at the formation time of the highly saturated hydrate zone (900$1500 \mathrm{~s}$ ), a significant decrease in the saturation of methane gas and liquid was also monitored, which was caused by the consumption of "raw materials" during the formation of hydrates.
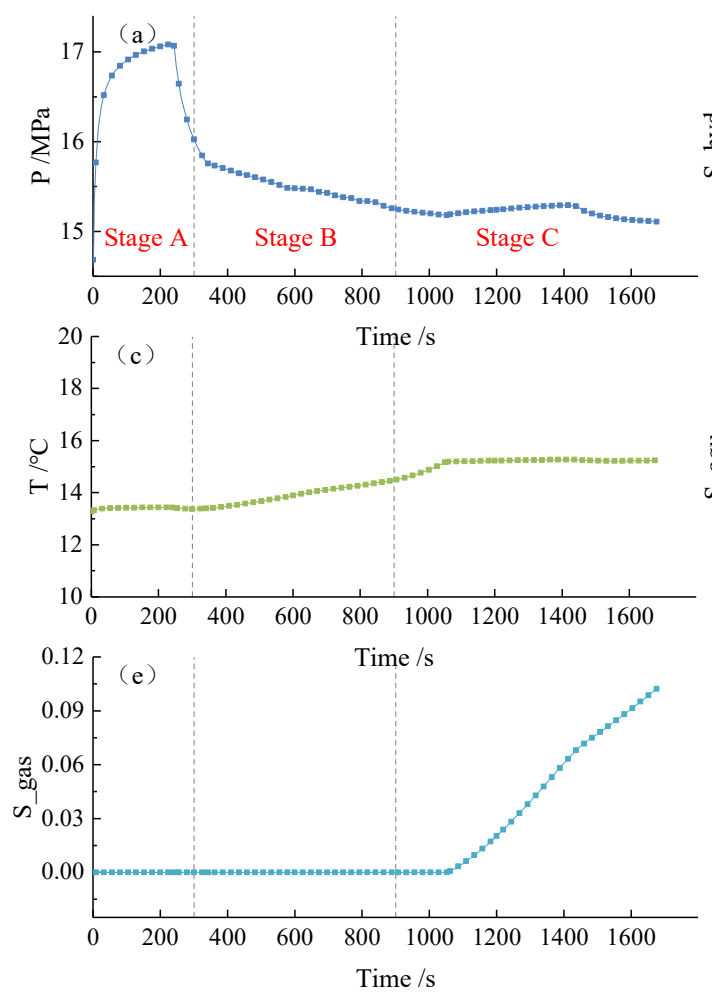

In summary, the entire simulation process can be divided into three stages, the induction stage, the hydrate decomposition stage and the secondary hydrate formation stage. The induction stage lasts for about $300 \mathrm{~s}$, during which the pressure and temperature both increase, but no hydrate decomposes, and the changes in gas and liquid saturation are mainly caused by the displacement effect caused by the invasion of cement slurry. The $300-900 \mathrm{~s}$ is the hydrate decomposition stage, in which the hydrate quickly decomposes, with a range of about $4 \mathrm{~cm}$, and the saturation of methane gas and liquid phase increases, with a range of about $6.5 \mathrm{~cm}$. The $900-1500 \mathrm{~s}$ is the secondary hydrate formation stage, in which, a highly saturated hydrate zone is formed in the range of 6-9 cm. Compared with the original reservoir saturation, the saturation of the newly formed area is increased by about $1.5 \%$. Finally, the influence range of pressure and temperature are about $1 \mathrm{~m}$ and $10 \mathrm{~cm}$, with an invasion depth of about $4 \mathrm{~cm}$. The decomposition range of hydrate is about $6 \mathrm{~cm}$, and the change range of gas and liquid is about $10 \mathrm{~cm}$.

\subsection{Formation and changes of highly saturated hydrate zone}

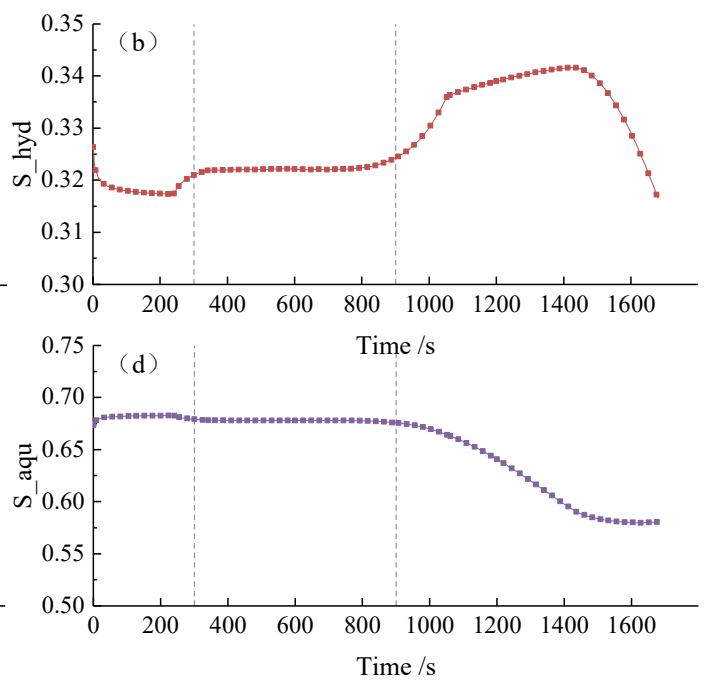
(a) Pore pressure
(b) Hydrate saturation
(c) Temperature
(d) Fluid saturation
(e) Gas saturation

Fig6. Changes in physical properties of high saturated hydrate zone (Stage A-- induction, Stage B-- hydrate decomposition, Stage C-secondary hydrate formation.)

In the simulation process, a monitoring point is set in the re-formed high-saturated hydrate zone, and the Changes in physical properties with time can be obtained, results are shown in Figure 6. During the induction phase, the pore pressure in this area increases rapidly, and the temperature remains basically unchanged. The hydrate saturation decreases slowly (to about $31.8 \%$ ), mainly due to the increase of porosity caused by fluid displacement into this area. In the hydrate decomposition stage, the displaced fluid dissipates to the depths of the formation, corresponding to the recovery of hydrate saturation, and no methane gas migrates to this area during this stage. Starting from $900 \mathrm{~s}$, the hydrate saturation increased rapidly and continued to about $1500 \mathrm{~s}$, with an increase of about 2\%. The gas produced by the previous decomposition also migrated into this area from about 
$1100 \mathrm{~s}$. At the same time, the rapid formation of hydrate corresponds to the decrease of pore water saturation and the increase of temperature.

\section{Conclusions}

This study established a two-dimensional cementing model for hydrate formations using TOUGH+HYDRATE, based on the field geological and technological parameters, and analyzed the main physical property changes of hydrate reservoirs during cementing. The main conclusions are as follows:

(1) During the cementing process, the invasion of cement slurry almost only occurs during the pressureholding period, and the invasion depth basically no longer increases after the removal of the holding pressure. The later impact of cement slurry on the reservoir is mainly caused by the exothermic heat of hydration, which leads to the change of the hydrate phase balance.

(2) The process of cement slurry invasion can be divided into three stages, they are the induction stage $(0-$ $300 \mathrm{~s})$, the hydrate decomposition stage (300-900 s) and the secondary hydrate formation stage (900-1500 s). Each stage corresponds to main area. The physical properties of hydrate reservoirs change most significantly during the hydrate decomposition stage.

(3) During the entire study stage, the influence range of pressure and temperature are about $1 \mathrm{~m}$ and $10 \mathrm{~cm}$, with an invasion depth of about $4 \mathrm{~cm}$. The decomposition range of hydrate is about $6 \mathrm{~cm}$, and the change range of gas and liquid is about $10 \mathrm{~cm}$.

(4) The "continuous stage simulation" used in this study can accurately restore the dynamic heat release process, and can well simulate and solve the issues of hydration heat release during well cementing.

\section{Acknowledgement}

This work was sponsored by the National Natural Science Foundation of China (No. 41702389, 41502346), National Key R\&D Program of China (2016YFE0204300), Key Laboratory of Tectonics and Petroleum Resources (China University of Geosciences), Ministry of Education (TPR2020-03), and Natural Science Foundation of Chengdu University of Technology (No.10912-2019KYQD-06874).

\section{References}

1. Sloan E. D., Koh C. (2008). Clathrate Hydrates of Natural Gases. London: CRC Press.

2. Sun J. Y., Li C. F., Hao X. L., et al. (2020). Study of the surface morphology of gas hydrate. Journal of Ocean University of China. 19(2): 331-338.

3. Liu X. Q., Xing L., Qin Z. L., et al. (2020). The sensitive properties of hydrate reservoirs based on seismic stereoscopic detection technology. Journal of Ocean University of China. 94(2): 530-544.

4. Huang L., Yin Z. Y., Wan Y. Z., et al. (2020). Evaluation and comparison of gas production potential of the typical four gas hydrate deposits in Shenhu area, South China Sea. Energy. 204:117955.

5. Xu H. F. (1990). Drilling Technical Manual (Third edition): Cementing. Beijing: Petroleum Industry Press.

6. Liu C. J., Huang B. Z., Xu T. T., et al. (2001). Theory and Application of Cement Injection in Oil and Gas Wells. Beijing: Petroleum Industry Press.

7. Wang R., Ning F. L., Liu T. L., et al. (2017). Dynamic simulation of free methane gas forming hydrate in the wellbore. Acta Petrolei Sinica. 8: 113-122.

8. Kamath V. A., Mutalik P. N., Sira J. H., et al. (1991). Experimental study of brine injection depressurization of gas hydrates dissociation. SPE Formation Evaluation. 6(4): 477-484.

9. Zhai C., Sun K. M., Xin L. W., et al. (2017). Numerical simulation study on deformation and failure of gas hydrate near well reservoir by thermal injection. Journal of Geomechanics. 23(6): 821-828.

10. Hao Y.M., Li X. Z., Tao S., et al. (2017). Discussion on heat transfer mode of thermal front in gas hydrate heat injection production. Natural Gas Industry. 37(12): 47-52.

11. Zheng M. M., Liu T. L., Jiang G. S., et al. (2020). Large-scale and high-similarity experimental study of the effect of drilling fluid penetration on physical properties of gas hydrate-bearing sediments in the Gulf of Mexico. Journal of Petroleum Science and Engineering. 187: 106832.

12. Zhang H. W., Cheng Y. F., Li L.D., et al. (2018). Disturbance simulation of intrusion of drilling fluid containing thermodynamic inhibitor into gas hydrate formation. Science Technology and Engineering. 18(6): 93-98.

13. Liu T. L., Zheng S. J., Wang Z., et al. (2018). Negative effect of cementing slurry invasion on gas hydrate stability around borehole wall. Acta Petrolei Sinica. 39(8): 937-946.

14. Moridis G. J. (2014). TOUGH + HYDRATE v1.2 User's Manual: A Code for the Simulation of System Behavior in Hydrate-bearing Geologic Media. Berkeley: Lawrence Berkeley National Laboratory. //http://escholarship.org/uc/item/3mk82656.

15. Wu N. Y., Zhang H. Q., Su X., et al. (2007). High concentrations of hydrate in disseminated forms found in very fine-grained sediments of Shenhu area, South China Sea. Terra Nostra. 1(2): 236-237.

16. Zhang H. Q., Yang S. X., Wu N. Y., et al. (2007). Successful and surprising results for China's first gas hydrate drilling expedition. Fire in the Ice Newsletter. 7(3): 6-9

17. Nakai T., Tjok K., Humphrey G. (2007). Deepwater gas hydrate investigation Shenhu survey area South China Sea, offshore China. Factual Field Report, Guangzhou Marine Geological Survey. Guangzhou, China.

18. Wang X. J., Wu S. G., Lee M., et al. (2011). Gas hydrate saturation from acoustic impedance and 
resistivity logs in the Shenhu area, South China Sea. Marine \& Petroleum Geology. 28(9):1625-1633.

19. Wang X. J., Hutchinson D. R., Wu S. G., et al. (2011). Elevated gas hydrate saturation within silt and silty clay sediments in the Shenhu area, South China Sea. Journal of Geophysical Research: Solid Earth. 116: B05102.

20. Wu N. Y., Zhang H. Q., Yang S. X., et al. (2007). Preliminary study on gas hydrate accumulation system in Shenhu area of South China Sea. Natural Gas Industry. $9: 1-6+125$.

21. Stone H. (1970). Probability model for estimating three-phase relative permeability. Journal of Petroleum Technology. 22(2): 214-218

22. Genuchten V. T. M. (1980). A closed-form equation for predicting the hydraulic conductivity of unsaturated soils. Soil ence Society of America Journal. 44(5): 892-898.

23. Moridis G. J., Seol Y., Kneafsey T. J. (2005). Studies of reaction kinetics of methane hydrate dissociation in porous media. Berkeley: Lawrence Berkeley National Laboratory.

//https://escholarship.org/uc/item/8q50w5cn. 